\title{
Pharmacological effects of the phytochemicals of Anethum sowa L. root extracts
}

\author{
Md Moshfekus Saleh-e-In 1*, Nasim Sultana², Md Nur Hossain ${ }^{3}$, Sayeema Hasan and Md Rabiul Islam
}

\begin{abstract}
Background: Anethum sowa L. is widely used as an important spice and traditional medicinal plants to treat various ailments. On the basis of scientific ethnobotanical information, this study was undertaken to evaluate the antioxidant, antimicrobial and cytotoxic activity of the crude extracts of Anethum sowa L. roots as well as to identify the classes of phytochemicals by chemical tests.

Methods: The antioxidant potential of the extracts was ascertained with the stable organic free radical $(2,2-$ diphenyl-1-picryl-hydrazyl). The agar well diffusion method was used to determine the susceptibility of bacterial and fungal strains of the crude extracts. The minimum inhibitory concentration (MIC) and minimum bactericidal concentrations (MBC) were determined by the microdilution test. Cytotoxic activities were screened using brine shrimps (Artemia salina) lethality assay. Finally, phytochemicals were profiled using standard procedures.

Results: A preliminary phytochemical screening of the different crude extracts by methanol, ethyl acetate and chloroform showed the presence of secondary metabolites such as flavonoids, alkaloids, saponin, cardiac glycosides and tannins while cyanogenetic glycosides were not detected. The methanol, ethyl acetate and chloroform extracts displayed high antioxidant activity $\left(\mathrm{IC}_{50}=13.08 \pm 0.03,33.48 \pm 0.16\right.$ and $36.42 \pm 0.41 \mu \mathrm{g} / \mathrm{mL}$, respectively) in the DPPH assay comparable to that of the standard ascorbic acid and $B H T\left(I C_{50}=3.74 \pm 0.05\right.$ and $\left.11.84 \pm 0.29 \mu \mathrm{g} / \mathrm{mL}\right)$. The cytotoxic activity of the crude ethyl acetate and chloroform extracts possessed excellent activity $\left(\mathrm{LC}_{50}=5.03 \pm\right.$ $0.08,5.23 \pm 0.11$ and $17.22 \pm 0.14 \mu \mathrm{g} / \mathrm{mL}$, respectively) against brine shrimp larvae after $24 \mathrm{~h}$ of treatment and compared with standard vincristine sulphate $\left(\mathrm{LC}_{50}=0.46 \pm 0.05 \mu \mathrm{g} / \mathrm{mL}\right)$. The extracts also showed good antimicrobial activity against both Gram-positive and Gram-negative bacteria when compared with two standard antibiotics ciprofloxacin and tetracycline.
\end{abstract}

Conclusion: These results showed that the Anethum sowa root extracts are the important source of the antioxidant, antimicrobial and cytotoxic agent. So, further research is necessary to isolate and characterize of different phytoconstituents for pharmaceutical drug lead molecules and also to verify its traditional uses.

Keywords: Anethum sowa L, Antioxidant, Cytotoxicity, Gram-positive bacteria, Gram-negative bacteria, Phytochemical screening

\footnotetext{
* Correspondence: saleheen.sosthe@gmail.com

${ }^{1}$ Department of Chemistry, Jahangirnagar University, Savar 1342, Dhaka,

Bangladesh

Full list of author information is available at the end of the article
} International License (http://creativecommons.org/licenses/by/4.0/), which permits unrestricted use, distribution, and reproduction in any medium, provided you give appropriate credit to the original author(s) and the source, provide a link to the Creative Commons license, and indicate if changes were made. The Creative Commons Public Domain Dedication waiver (http://creativecommons.org/publicdomain/zero/1.0/) applies to the data made available in this article, unless otherwise stated. 


\section{Background}

Plant derived natural products are known to play an important role in both drug discovery and chemical biology. The medicinal properties of plants have been investigated due to their potent pharmacological activities, low toxicity and economic viability $[1,2]$. There is an abundance of medicinal plants throughout the world, but only limited numbers have been investigated for its biological and pharmacological properties [3]. Plant phytochemicals have a significant role in the plants defense mechanism and also important for their unambiguous physiological action in the human body. Specially the secondary metabolites are becoming a part of the integrated health care system as supportive and alternative medicines because of their therapeutic property [4]. Therefore, it is essential to study the medicinal plants so that the discovery of active natural products ingredient can be identified for healing diseases. Later on, the identified active ingredients could be synthesized in the laboratory.

Anethum sowa L. (Bengali-Shulfa) belonging to the family Apiaceae (Umbelliferae), is a common aromatic and spice herb known as Shulfa in Bangladesh and found as a Dill in Europe, Asia-temperate, Africa and Asian-tropical countries. Indigenous people consume it as a spice for a flavouring agent in culinary preparation. The herb grows ordinarily $2-2.5 \mathrm{ft}$. in height with small feathery leaves, tapped and branched roots $[5,6]$. The green herb, seeds and its roots are used as folkloric medicine e.g. aromatic, carminative especially useful in flatulence, colic and hiccups of infants and children [7]. The insecticidal, ovicidal and synergistic activity of dillapiol and essential oil of the seed part are well known [8]. Moreover, it was reported that seed essential oils are the potential source of antioxidant and also have antimicrobial and antispasmodic properties [9]. Recently the phytochemical screening, anti-depressant and analgesic effects of aqueous extracts by Anethum graveolens L. has been reported [10]. Abbas et al. [11] also reported the lipid-lowering of hydroalcoholic extract of Anethum graveolens L.

Antioxidants protect cells against damage caused by molecules known as free radicals. Free radicals result from an imbalance between the generation of Reactive Oxygen Species (ROS) and the antioxidant protection conferred by enzymatic systems. The oxidation induced by ROS can result in cell membrane disintegration, membrane protein damage and DNA mutation. Overproduction of ROS can result in progression of many diseases, such as cancer, diabetes, liver injury, arteriosclerosis, cardiovascular disease and lead to agingrelated disorders [12]. The quest for natural antioxidants for dietary, cosmetic and pharmaceutical uses have become a major industrial and scientific research challenge over the last two decades. Plant secondary metabolites, mainly in the form of phenolic and nitrogen compounds as well as carotenoids and ascorbic acid have been reported to exhibit antioxidant and anticancer activities [13]. Synthetic antioxidants are commonly used in processed foods which have side effects and also reported carcinogenic [14]. Currently, there has been a growing interest of many research groups to identify plantderived natural antioxidant compounds that are pharmacologically potent and have nutritional and therapeutic value.

In recent years, multiple drug resistance in human pathogenic microorganism has been developed due to indiscriminate use of commercial antimicrobial drugs commonly used in the treatment of various diseases. Plant biomolecules (phytochemicals) have been reported to be alternatives to antibiotic resistance of human pathogens because of their proven effectiveness and availability [15]. Therefore, the search for new antimicrobial substances from various medicinal plants through isolation and characterization of their constituents is warranted.

Bioactive compounds are almost always toxic in high doses. Pharmacology is simply toxicology at a lower dose and toxicology is simply pharmacology at a higher dose. Bioactive compounds are often toxic to shrimp larvae. Hence, in vivo lethality to shrimp larvae can be used as a rapid, simple, preliminary bioassay for testing plant extracts and organic compounds which in most cases correlates reasonably well with cytotoxic and anti-tumor properties [16]. Moreover, this test is also considered to be very useful in determining various biological activities such as phototoxic, pesticidal, trypanocidal, enzyme inhibition and ion regulation activities [17].

Despite some folklore use of this plant, there is no scientific report documented in the information on its phytochemical, antioxidant and antimicrobial as well as cytotoxic properties of this plant to the best of our knowledge. In this study, we sought to interrogate the antioxidant, anti-microbial and cytotoxic effect compared with the commercial standard as well as the screening of phytoconstituents of Anethum sowa L. root extracts.

\section{Methods}

\section{Plant material}

Whole plants were collected from Keranigonj, Dhaka of Bangladesh after harvesting. The plant was authenticated by Dr. Sardar Nasir Uddin, PSO, Bangladesh National Herbarium, Dhaka, Bangladesh. Voucher specimen with Accession Number-31,282 was placed at the Herbarium. Shade dried roots were powdered in a grinding machine to 100 mesh and stored in the airtight high-density polyethylene bag for solvent extraction. 


\section{Chemicals and reagents}

The chemicals n-hexane, chloroform, ethyl acetate and methanol (Merck Germany) were used for solvent extraction. The laboratory grade petroleum ether (bp. $40-60{ }^{\circ} \mathrm{C}$ ) was collected from fuel petrol by fractional distillation. 1,1-diphenyl-2-picrylhydrazyl (DPPH) was purchased from Sigma-Aldrich, Munich, Germany. Butylated Hydroxytoluene (BHT) and ascorbic acid (BDH, England) were used as reference standard for free radical scavenging assay. Ciprofloxacin $(5 \mu \mathrm{g} /$ disc), tetracycline $(30 \mu \mathrm{g} /$ disc $)$ (Oxoid, England) and fluconazole $(100 \mu \mathrm{g} / \mathrm{mL}$ ) (AFC Bangladesh) were used as the reference standard and positive control for antibacterial screening assay. Vincristine sulfate (Merck, Germany) was used as a reference cytotoxic agent in the brine shrimp lethality test.

\section{Preparation of the extracts}

The powder material $(1.5 \mathrm{~kg})$ of Anethum sowa L. root was extracted successively with petroleum ether (b.p. $40-60{ }^{\circ} \mathrm{C}$ ), chloroform, ethyl acetate and methanol at room temperature. Extractions were carried out three times in 3-4 days of each solvent with frequent shaking. Removal of solvent from powder materials was done by filtration through cheesecloth and Whatman filter paper No. 1. The filtrate was then further concentrated under reduced pressure by a rotary evaporator (Buchi, R-15v) at low temperature. The chloroform, ethyl acetate and methanol extract were triturated with pet.ether $(3 \times 50 \mathrm{~mL})$ of each time for $2 \mathrm{~h}$ at room temperature to get the fat free extract. The pet.ether soluble extracts were combined with pet.ether extract. On the other hand, the certain amount of root powdered sample of Anethum sowa L. was carried out in hot extraction process by Soxhlet apparatus with hexane at room temperature for $72 \mathrm{~h}$.

\section{Qualitative phytochemical group tests}

The extracts were subjected to qualitative screening for the detection of phytochemical groups by established methods [18-20]. In each test $10 \%(\mathrm{w} / \mathrm{v})$ solution of the extract was taken unless otherwise mentioned in the individual test.

\section{Antioxidant activity (DPPH assay)}

The free radical scavenging effect of $A$. sowa root extracts, ascorbic acid (ASA) and tert-butyl-1-hydroxytoluene (BHT) were assessed with the stable scavenger DPPH with slight modifications of the method described by Brand-Williams [21]. Briefly, the calculated amount (about $2 \mathrm{mg}$ ) of different extracts, ASA and BHT were dissolved in methanol to get a mother solution having a concentration $1000 \mu \mathrm{g} / \mathrm{mL}$. ASA and BHT were used as positive control. DPPH solution $(40 \mu \mathrm{g} / \mathrm{mL})$ was prepared in methanol. The solution was prepared in the amber reagent bottle, kept in the light-proof box with ice. The degree of DPPH-purple decolorization to $\mathrm{DPPH}$-yellow indicated the scavenging efficiency of the sample. Serial dilutions were made using the mother solution to get different concentrations (200, $100,50,25,12.5,6.25,3.125$ and $1.562 \mu \mathrm{L}) .200 \mu \mathrm{L}$ of a sample solution (extracts or control) at different concentration and $800 \mu \mathrm{L}$ methanol (total $1000 \mu \mathrm{L}$ ) were mixed with $1000 \mu \mathrm{L}$ of a DPPH solution. Incubation was performed for $25 \mathrm{~min}$ for reaction at room temperature $\left(25^{\circ} \mathrm{C}\right)$ in the dark place. The absorbance was measured at $517 \mathrm{~nm}$ against methanol as blank by UV-Visible spectrophotometer (UV-VIS 1650, Shimadzu Corporation, Japan). The lower absorbance of the reaction mixture indicated higher free radical scavenging activity. The percentage of inhibitions were calculated from the equation: $\%$ inhibition $=\left(1-\mathrm{ABS}_{\text {sample }} / \mathrm{ABS}_{\text {blank }}\right) \times 100$. Where $\mathrm{ABS}_{\text {blank }}$ is the absorbance of the DPPH solution (control) and $\mathrm{ABS}_{\text {sample }}$ for the sample or standard absorbance. Then the percentage of scavenging of the extract was compared with positive control.

\section{$I_{50}$ value of the extract}

The $\mathrm{IC}_{50}$ value data were transformed into a straight line by means of a trend line fit linear regression analysis by MS Excel version 7 Software for Windows. The $\mathrm{IC}_{50}$ values were calculated as the concentration of each sample required to give $50 \% \mathrm{DPPH}$ radical scavenging activity from the graph (linear regression curve) by Excel 2007 Office Software. The lower IC $_{50}$ value indicates the higher radical scavenging effect. The experiment was performed triplicate and the results were expressed as mean \pm SD with $95 \%$ confidence interval in every case.

\section{Cytotoxic activity by Brine Shrimp lethality bioassay}

In vitro Brine Shrimp lethality bioassay of the dried extracts were exploited to detect cytotoxicity by the Mayer's method [17]. Brine Shrimp (Artemia salina) eggs were hatched in a brine solution $(3.8 \% \mathrm{NaCl}$ in distilled water) within $48 \mathrm{~h}$. The samples were prepared by dissolving in DMSO solution (not more than $50 \mu \mathrm{L}$ in $5 \mathrm{~mL}$ solution) and it was applied in $5 \mathrm{~mL}$ brine solution to attain the concentrations of 0.0195 to $10.0 \mu \mathrm{g} / \mathrm{mL}$. DMSO $(50 \mu \mathrm{L})$ used as negative control. Standard vincristine sulfate (VCS) $(0.078 \mu \mathrm{g} / \mathrm{mL}$ to $10.0 \mu \mathrm{g} / \mathrm{mL})$ was used as positive control. Approximately 10 matured nauplii were taken to each vial. The number of surviving nauplii was counted after $24 \mathrm{~h}$. The lethal concentrations $\left(\mathrm{LC}_{50}\right)$ and the dose-response data were calculated from the linear regression graph by Excel 2007 Software. 


\section{Antimicrobial activity of the plant extracts Microorganism}

Gram-positive (Bacillus subtilis, Staphylococcus aureus, Bacillus cereus, Enterococcus faecalis) and Gram-negative bacteria (Salmonella typhi, Escherichia coli 12079, Escherichia coli 2799, Pseudomonas aeruginosa, Salmonella enteritidis, Acetobacter aceti) were used for antibacterial screening and Aspergillus niger, Candida albicans and Trichoderma sp. were used for fungal studies. All the stock cultures were collected from the Industrial Microbiology Division, Bangladesh Council of Scientific and Industrial Research, Dhaka, Bangladesh.

Media preparation and maintenance of bacteria and fungi All the bacterial and fungal strains were grown and maintained on Mueller Hinton agar (Himedia, India) media at $37{ }^{\circ} \mathrm{C}$ and $\mathrm{pH}(7.3 \pm 0.2)$. The bacteria and fungi were subcultured overnight Mueller Hinton broth, which was further adjusted to obtain turbidity comparable to McFarland (0.5) standard when required [22].

\section{Antibacterial screening by diffusion technique}

The antibacterial activity of the dried extracts was determined by diffusion and dilution method [23] against $4 \mathrm{~g}$ positive, 6 g-negative bacteria and 3 fungi species. The test microbes were taken from the broth culture with an inoculating loop and transferred to the test tubes containing $5.0 \mathrm{~mL}$ sterile distilled water. The bacterial suspension turbidity adjusted to McFarland standard number 0.5, in Mueller Hinton Broth (Himedia, India). A cotton swab was then used to inoculate the test tube suspension onto the surface of the Mueller Hinton agar plates and the plates were allowed to dry. The agar was allowed to set and harden. Holes were made by using a sterile cork borer from each petri-plate to ensure proper distribution of holes (cups) in the periphery and one in the center. Agar plugs were removed. Different cork borers were used for different test organisms. Two standard discs $(6 \mathrm{~mm}$ in diameter) ciprofloxacin and tetracycline were transferred onto the agar surface by using sterile forceps. Each hole was impregnated with $40 \mu \mathrm{L}$ of a sample solution containing 800,1200 and $2000 \mu \mathrm{g}$ sample. This was done also for methanol (negative control) as a blank. These plates were kept for an hour at a low temperature, so that the test materials were diffused into the surrounding medium by this time. The plates were then incubated at $37{ }^{\circ} \mathrm{C} \pm 1{ }^{\circ} \mathrm{C}$ for $24 \mathrm{~h}$. The diameter of the inhibition zone against each microorganism by plant extracts was measured by digital calipers (Deko Corporation, China, accuracy $0.02 \mathrm{~mm}$ and resolution $0.01 \mathrm{~mm}$ ) and compared the results with standard antibiotic ciprofloxacin $(5 \mu \mathrm{g} /$ disc $)$ and tetracycline $(30 \mu \mathrm{g} / \mathrm{disc})$ as a positive control.
MIC and MBC determination by dilution technique Minimum Inhibitory Concentrations (MIC) and Minimum Bactericidal Concentrations (MBC) of the plant extracts were carried out by the macro-dilution method $[24,25]$. The plant extracts were dissolved in $30 \%$ dimethyl sulfoxide (DMSO) to obtain $10 \%(\mathrm{w} / \mathrm{v})$ solution. For MIC test of the selected bacteria, the extracts were first diluted in sterilized Mueller-Hinton broth in screw capped tubes containing broth medium in the concentration of 1000, 500, 250, 125, 62.5 and $31.25 \mu \mathrm{g} / \mathrm{mL}$. Bacterial suspensions of the test organism were prepared in sterilized Mueller-Hinton broth. $1 \mathrm{~mL}$ of the dilution was added to each sterilized screw capped tube containing $1 \mathrm{~mL}$ of sample suitably diluted in the sterilized broth medium to give a final volume of $2 \mathrm{~mL}$. A culture medium without sample (solvent DMSO) was used as a negative control. Ciprofloxacin $(100-0.191 \mu \mathrm{g} / \mathrm{mL}$.) was used as positive control. Tubes were incubated aerobically at $37{ }^{\circ} \mathrm{C}$ for $24 \mathrm{~h}$ and the growth was indicated by turbidity. The lowest concentration preventing visible growth (no turbidity) was identified as the MIC and expressed in $\mu \mathrm{g} / \mathrm{mL}$. The complete absence of growth was considered as the MBC [26]. To confirm the results of the $\mathrm{MBC}, 10 \mu \mathrm{L}$ of the experimental suspensions (withdrawn from the tubes with no growth) were subcultured on TSA (Tryptone Soy Agar) plates. The Plates were incubated at $37{ }^{\circ} \mathrm{C} \pm 1{ }^{\circ} \mathrm{C}$ for $24 \mathrm{~h}$. It showed no bacterial growth, which was taken as the MBC. Values were recorded as $\mu \mathrm{g} / \mathrm{mL}$.

\section{Antifungal assay}

The antifungal activity test was performed by a similar procedure as an antibacterial activity test. But the PDA growth medium was used instead of NA medium. Positive control (Flucanozole $100 \mu \mathrm{g} / \mathrm{mL}$ ) and extracts containing petri dishs were incubated at $25 \pm 2{ }^{\circ} \mathrm{C}$ for $72 \mathrm{~h}$. The MICs and MBCs of the selected fungi were also done by the micro dilution method as described in the antibacterial activity test.

\section{Statistical analysis}

Statistical analysis of all data was performed by means of the Microsoft Excel 7.0 version for Windows. All data are presented as mean value \pm standard deviation $(n=3)$. The values were considered significantly different at $(P<0.05)$.

\section{Results and discussion} Plant extract

Successive extraction of Anethum sowa L. (1.5 kg) root powder yielded (\%) $0.60,0.35,0.72,1.14$ and 1.40 by petroleum ether, chloroform, ethyl acetate, hexane and methanol respectively (Table 1 ). The highest yield (20.94 g) was obtained from methanol crude extract. 
Table 1 A. sowa root extracts yield

\begin{tabular}{llllll}
\hline \multicolumn{5}{c}{ Crude extracts } \\
\cline { 2 - 6 } & PE & CE & EtOAc & Hex. Hot & MeOH \\
\hline Yields in grams (g.) & 9.03 & 5.24 & 10.70 & 2.85 & 20.94 \\
Yields in percentage (\%) & 0.60 & 0.35 & 0.72 & 1.14 & 1.40 \\
Petroleum ether (PE), chloroform (CE), ethyl acetate (EtOAc), hexane hot \\
extract (Hex. Hot), methanol (MeOH)
\end{tabular}

\section{Phytochemical screening of extracts}

Qualitative phytochemical tests of Anethum sowa L. were performed for the methanol $(\mathrm{MeOH})$, ethyl acetate (EtOAc), chloroform (CE), pet-ether (PE cold) and hexane (Hex.hot) extracts of the root. The results of various chemical tests for the detection and identification of chemical constituents were summarized in Table 2. In the present study, flavonoids, glucosides, cardiac glycosides and anthraquinone glycosides were present in $\mathrm{MeOH}, \mathrm{EtOAc}$ and $\mathrm{CE}$ extracts, but in addition, the saponins were present only in $\mathrm{MeOH}$ extract. Steroids were found in all the extract except $\mathrm{MeOH}$ extract. On the other hand, all the groups were absent in PE (cold) and Hex.(hot) extracts except steroids. However, alkaloids, carbohydrates and tannins were highly present in the $\mathrm{MeOH}$ extract whereas, EtOAc extract showed slightly positive test for alkaloids and absent in CE extract. The carbohydrates showed slightly positive in $\mathrm{CE}$ and EtOAc extract.

The value of medicinal plants is due to phytochemical constituents or secondary metabolites that synthesized by the plant body during the plants normal metabolic processes and plants use them to protect themselves against different pathogenic attack [27]. The optimal effectiveness of a medicinal plant may not be due to the one main active constituent, but may be due to the combined action of different compounds originally in the plant [28]. Cardiac glycosides work by inhibiting the $\mathrm{Na}$ ${ }^{+} / \mathrm{K}^{+}$pump. This causes an increase in the level of sodium ions in the myocytes, which then leads to a rise in the level of calcium ions. This inhibition increases the amount of $\mathrm{Ca}^{2+}$ ion available for contraction of the heart muscle, improves cardiac output and reduces distention of the heart [29]. Cardiac glycosides were found to be present in $\mathrm{MeOH}$, EtOAc and CE extracts, it can be aided in treatment for congestive heart failure and cardiac arrhythmia. Alkaloids are nitrogen-containing

Table 2 Phytochemical constituents of different extracts (PE, Hex, CE, EtOAc and MeOH) of Anethum sowa L. root

\begin{tabular}{|c|c|c|c|c|c|c|}
\hline \multirow[t]{2}{*}{ Metabolites } & \multicolumn{6}{|l|}{ Tests } \\
\hline & & PE (Cold) & Hex (Hot) & CE & EtOAc & $\mathrm{MeOH}$ \\
\hline \multirow[t]{2}{*}{ Saponins } & a) Frothing & a) $(-)$ & a) $(-)$ & a) $(-)$ & a) $(-)$ & a) $(+++)$ \\
\hline & b) Emulsification & b) $(-)$ & b) $(-)$ & b) $(-)$ & b) $(-)$ & b) $(+++)$ \\
\hline \multirow[t]{2}{*}{ Flavonoids } & a) Alkaline reagent Test & a) $(-)$ & a) $(-)$ & a) $(+++)$ & a) $(+++)$ & a) $(+++)$ \\
\hline & b) Lead acetate Test & b) $(-)$ & b) $(-)$ & b) $(++)$ & b) $(++)$ & b) $(++)$ \\
\hline \multirow[t]{3}{*}{ Alkaloids } & a) Mayers' reagents & a) $(-)$ & a) $(-)$ & a) $(-)$ & a) $(+)$ & a) $(+++)$ \\
\hline & b) Hager's Test & b) $(-)$ & b) $(-)$ & b) $(-)$ & b) $(+)$ & b) $(++)$ \\
\hline & c) Wagner's Test & c) $(-)$ & c) $(-)$ & c) $(-)$ & c) $(+)$ & c) $(++)$ \\
\hline \multirow[t]{2}{*}{ Steroids } & a) Salkowski test: & a) $(+++)$ & a) $(+++)$ & a) $(+++)$ & a) $(+++)$ & a) $(-)$ \\
\hline & b) Liebermann-Burchard's test & b) $(+++)$ & b) $(+++)$ & b) $(+++)$ & b) $(+++)$ & b) $(-)$ \\
\hline \multirow[t]{2}{*}{ Carbohydrates } & a) Molisch's test & a) $(-)$ & a) $(-)$ & a) $(+)$ & a) $(+)$ & a) $(+++)$ \\
\hline & b) Fehling test for reducing sugar & b) $(-)$ & b) $(-)$ & b) $(-)$ & b) $(-)$ & b) $(+++)$ \\
\hline \multirow[t]{2}{*}{ Glucosides } & a) General test & a) $(-)$ & a) $(-)$ & a) $(++)$ & a) $(++)$ & a) $(+++)$ \\
\hline & b) Test for glucosides & b) $(-)$ & b) $(-)$ & b) $(+)$ & b) $(+)$ & b) $(+++)$ \\
\hline \multirow[t]{2}{*}{ Cardiac glycosides } & a) Keller Killiani test & a) $(-)$ & a) $(-)$ & a) $(+++)$ & a) $(+++)$ & a) $(+++)$ \\
\hline & b) Baljet Test & b) $(-)$ & b) $(-)$ & b) $(+++)$ & b) $(+++)$ & b) $(+++)$ \\
\hline \multirow[t]{3}{*}{ Anthraquinone glycosides } & a) Borntrager's Test & & & & & \\
\hline & i) O-glycoside & i) $(-)$ & i) $(-)$ & i) $(++)$ & i) $(++)$ & i) $(+++)$ \\
\hline & ii) C-glycoside & ii) $(-)$ & ii) $(-)$ & ii) $(-)$ & ii) $(-)$ & ii) $(-)$ \\
\hline \multirow[t]{3}{*}{ Tannins } & a) Gelatin-salt block test: & a) $(-)$ & a) $(-)$ & a) $(-)$ & a) $(-)$ & a) $(+++)$ \\
\hline & b) Lead acetate test & b) $(-)$ & b) $(-)$ & b) $(-)$ & b) $(++)$ & b) $(+++)$ \\
\hline & c) Condensed or Phlobatanins & c) $(+++)$ & c) $(+++)$ & c) $(++)$ & c) $(++)$ & c) $(++)$ \\
\hline Cyanogenetic glycosides & a) Sodium picrate test & a) $(-)$ & a) $(-)$ & a) $(-)$ & a) $(-)$ & a) $(-)$ \\
\hline
\end{tabular}

$(-)=$ negative (absent), $(+)=$ Positive (slightly present), $(++)=$ Positive (moderately present), $(+++)=$ Positive (Abundantly present) 
naturally occurring compound, commonly found to have antimicrobial properties due to their ability to intercalate with the DNA of the microorganisms [30]. Flavonoids and tannins are phenolic compounds and plant phenolics are a major group of compounds that act as primary antioxidants of free radical scavengers [31]. Flavonoids are also found to be effective antimicrobial substances in vitro against a wide array of microorganisms by inhibiting the membrane bound enzymes. They have been reported to possess substantial anti-carcinogenic and anti-mutagenic activities due to their anti-oxidant andinflammatory properties. They are also active in reducing high blood pressure [30]. On the other hand, tannins play a major role as antihaemorrhagic agent and have been shown to have immense significance as antihyper cholesterol, hypotensive and cardiac depressant properties [32]. Glycosides serve as defense mechanisms against predation by many microorganisms, insects and herbivores [33]. Moreover, glycosides, flavonoids, tannins and alkaloids have hypoglycemic activities [34]. Saponins are another type of bioactive chemical constituents which are involved in plant disease resistant because of their antimicrobial activity [35]. On the other hand, saponins have been shown to possess both beneficial (cholesterollowering) and deleterious (cytotoxic; permeabilization of the intestine) properties [36]. Although, some saponins have been shown to be highly toxic under experimental conditions and acute poisoning is relatively rare both in animals and man [37]. Hypocholesterolemic and antidiabetic properties of saponins are also reported [38]. Medicinal plants are the best sources for chemical ingredients. Based on preliminary phytochemical studies, the results revealed that Methanol, ethyl acetate and chloroform crude extracts of $A$. sowa root contained larger amounts of bioactive secondary metabolites that may be potential as chemotherapeutic drugs.

\section{Antioxidant activity on DPPH radical}

The free radical scavenging activity of the root extracts of Anethum sowa L. were measured by DPPH assay and the summarized results are shown in Table 3. All the extract showed a significant DPPH scavenging activity in a concentration dependent manner. The lower the $\mathrm{IC}_{50}$ value is, the greater the free radical scavenging activity is. For each sample eight concentrations $(1.562-200 \mu \mathrm{g} / \mathrm{mL})$ were tested. Methanol extract exhibited considerably higher DPPH radical scavenging activity $\left(96.18 \%\right.$ ) with the $\mathrm{IC}_{50}$ value of $13.08 \mu \mathrm{g} / \mathrm{mL}$ than other extracts and the lowest (33.71 \%) DPPH scavenging rate was found in the hexane (hot) extract with the $\mathrm{IC}_{50}$ value of $8.33 \mathrm{mg} / \mathrm{mL}$. The free radical scavenging activities of the extracts decreased in the order of methanol $>$ ethyl acetate $>$ chloroform $>$ pet.ether(cold) $>$ hexane(hot). The $\mathrm{IC}_{50}$ values were also shown in Table 3. The ethyl acetate and chloroform extract showed the significant radical scavenging activity of 87.11 and $74.97 \%$ with the $\mathrm{IC}_{50}$ values of $33.48 \mu \mathrm{g} / \mathrm{mL}$ and $36.42 \mu \mathrm{g} / \mathrm{mL}$ respectively. The $\mathrm{IC}_{50}$ value of the extract was found to be very fair compared to the $\mathrm{IC}_{50}$ value of the reference standard ASA $(3.74 \mu \mathrm{g} / \mathrm{mL})$ and BHT $(11.84 \mu \mathrm{g} / \mathrm{mL})$ with the highest inhibition of 99.05 and $93.02 \%$ respectively. Moreover, the methanol extract showed the same radical scavenging activity like a standard at the same concentrations.

Antioxidant activity depends on their scavenging powers which are useful for the management of many disorders like atherosclerosis, angina pectoris, neurodegenerative diseases and cancer diseases. Many synthetic antioxidants such as butylated hydroxy anisole (BHA) and butylated hydroxyl toluene (BHT) are commercially available and widely used, but they may possess some side effects and toxic properties to human health [39]. So, attention has been directed towards the natural antioxidants from botanical sources, especially plants. However, a significant correlation is observed between the antioxidant activity of herbs and the phytochemical content.

Plant phenolic compounds or poliphenols are the natural antioxidants which can act as a free radical scavenger, metal chelators and singlet oxygen quenchers and as a multi-functional activity [40]. The anti-oxidative potential of flavonoid depends on their chemical structure. The hydroxyl groups of phenolic compounds allow them to exert direct anti-oxidative activity and were found to play a vital role in stabilizing lipid peroxidation. The most active antioxidant compound is catechol, which possesses two hydroxyl groups in the ortho position. The first chain carrying peroxyl radical was being trapped by $\mathrm{H}$-atom transfer from the labile phenolic $\mathrm{O}-\mathrm{H}$ and the second by reaction with the resultant phenoxyl radical [40] and produced stable quinines upon oxidation. This property renders these phenolic compounds as efficient antioxidants.

The presence of phenolic constituents like flavonoids and tannins in the phytochemical study may have contributed to the observed antioxidant activity of this plant parts. Therefore, phenolic compounds in Anethum sowa root extracts are good electron donors and could terminate the radical chain reaction by converting free radicals to more stable products. The high antioxidant activity shown by the methanolic extract of the root suggests that it is a potential therapeutic agent for the control of oxidative damage caused by reactive oxygen species.

\section{Brine shrimp cytotoxicity assay}

The brine shrimp cytotoxicity of the plant extract represents a rapid, inexpensive and simple bioassay technique for cytotoxic, anti-tumor and anticancer activity. This test is also considered to be phototoxic, pesticidal, trypanocidal, antitumor, enzyme inhibition and ion regulation activities. The brine shrimp cytotoxicity bioassay of 


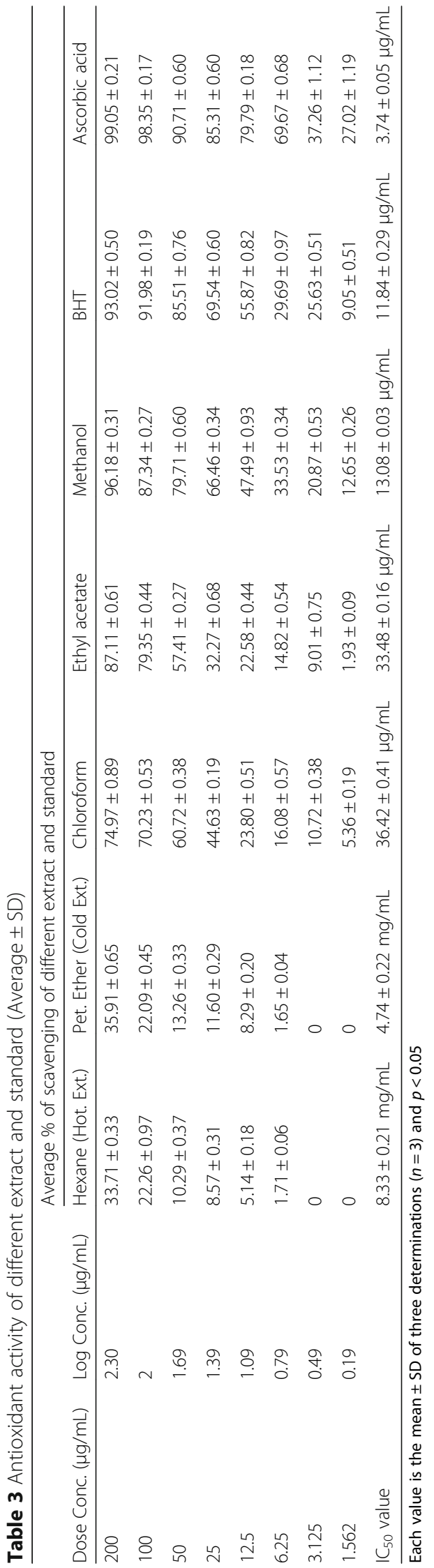


Anethum sowa L. root extracts and that of the positive control vincristine sulphate are summarized in Table 4 . The extract showed lethality in a dose-dependent manner. All the extracts exhibited significant toxicity towards brine shrimps at $24 \mathrm{~h}$. The $\mathrm{LC}_{50}$ value of the methanol extract was found the highest cytotoxicity at the $\mathrm{LC}_{50}$ value of $5.03 \mu \mathrm{g} / \mathrm{mL}$ with the $100 \%$ mortality at 400 and $200 \mu \mathrm{g} / \mathrm{mL}$ dose levels followed by ethyl acetate $(5.23 \mu \mathrm{g} / \mathrm{mL})$, chloroform $(17.22 \mu \mathrm{g} / \mathrm{mL})$, pet ether (cold) $(48.71 \mu \mathrm{g} / \mathrm{mL})$ and hexane (Hot) $(51.90 \mu \mathrm{g} / \mathrm{mL})$ extracts. The activity of ethyl acetate extract was found to almost same as methanol extract. In comparison to standard positive control vincristine sulphate $\left(\mathrm{LC}_{50}=\right.$ $0.46 \mu \mathrm{g} / \mathrm{mL}$ ), the ethyl acetate and methanol extract were found promising. Moreover, chloroform extract found moderate activity. On the other hand, hexane (hot) and pet ether (cold) extract demonstrate the lower activity. Higher mortality was observed in the every extract at $400 \mu \mathrm{g} / \mathrm{mL}$ concentration dose levels.

Bioactive compounds are almost always toxic in high doses. In the brine shrimp lethality assay, the degree of lethality was directly proportional to the concentration of the crude extracts of the $A$. sowa root. The cytotoxic activity is recommended weak at the $\mathrm{LC}_{50}$ is 500 $1000 \mu \mathrm{g} / \mathrm{mL}$, moderate at $100-500 \mu \mathrm{g} / \mathrm{mL}$ and strong at $0-100 \mu \mathrm{g} / \mathrm{mL}$ [41]. However, according to Mayer [17], extracts derived from natural products which have $\mathrm{LC}_{50} \leq 1.0 \mathrm{mg} / \mathrm{mL}$ are known to possess toxic effects. Conclusively, our results showed that all the extracts could be regarded as toxic to brine shrimp larvae cells based on the $\mathrm{LC}_{50}$ values in the current study. The $A$. salina embryos are highly vulnerable to toxins at early developmental stages [42]. A dose dependent relationship was observed where the percent of toxicity increased with increase in the concentration of the extracts. Bioassay-guided fractionation offers special advantages for identification of medicinal plant extracts. Most often, a desired biological response is not due to one component but rather due to a mixture of bioactive plant components [43]. Özçelik reported [44] the cytotoxic effect of plants is principally contributed by the presence of secondary metabolites like alkaloid, glycosides, steroid, tannin and flavonoids. Steroids, flavonoids and saponins which may also responsible for the prominent cytotoxic effect in brine shrimp lethality bioassay [45]. It has been established that the cytotoxic compounds generally exhibit significant activity in the brine shrimp lethality assay. Preliminary phytochemical screening of the extracts showed the presence of alkaloids, tannins, saponins and flavonoids type compounds in methanol, ethyl acetate and chloroform extract prominently. This assay can be recommended as a guide for the detection of antitumour and pesticidal compounds because of its simplicity and low cost. Further toxicity studies on individual cell line are also suggested to confirm the anticancer effect of the Anethum sowa L. root extracts.

\section{Antimicrobial activity of Anethum sowa L. root extracts}

The antibacterial activity of Anethum sowa L. root extracts was tested in vitro by using diffusion and liquid dilution method. The extracts were tested against 10 pathogenic bacteria. The antibacterial activity of the extracts was assessed by determining their ZI, MIC and MBC values and shown in Tables 5, 6, 7 and 8. The

Table 4 Cytotoxic activity of different extract and standard (Average \pm SD)

\begin{tabular}{|c|c|c|c|c|c|c|c|}
\hline & & & & & & Vincristine & Sulphate \\
\hline $\log$ Conc. $(\mu \mathrm{g} / \mathrm{mL})$ & Pet. Ether (Cold Ext.) & Hexane (Hot. Ext.) & Chloroform & Ethyl acetate & Methanol & $\begin{array}{l}\log \text { Conc. } \\
(\mu \mathrm{g} / \mathrm{mL})\end{array}$ & $\begin{array}{l}\text { Average \% of } \\
\text { mortality }\end{array}$ \\
\hline 2.602 & $80.60 \pm 1.04$ & $80.60 \pm 1.04$ & $100 \pm 0.00$ & $100 \pm 0.00$ & $100 \pm 0.00$ & 1 & $100 \pm .00$ \\
\hline 2.301 & $70.21 \pm 1.11$ & $70.21 \pm 1.11$ & $90.85 \pm 0.83$ & $100 \pm 0.00$ & $100 \pm 0.00$ & 0.698 & $90.85 \pm 0.83$ \\
\hline 2 & $59.95 \pm 1.60$ & $59.95 \pm 1.60$ & $70.65 \pm 1.83$ & $91.06 \pm 1.15$ & $93.17 \pm 0.27$ & 0.397 & $80.12 \pm 1.62$ \\
\hline 1.698 & $48.48 \pm 2.62$ & $46.08 \pm 0.60$ & $59.95 \pm 1.60$ & $81.71 \pm 1.66$ & $84.55 \pm 1.19$ & 0.096 & $60.51 \pm 0.88$ \\
\hline 1.397 & $39.48 \pm 0.88$ & $35.13 \pm 1.59$ & $46.08 \pm 0.60$ & $81.88 \pm 1.91$ & $73.48 \pm 1.31$ & -0.204 & $50 \pm 0.00$ \\
\hline 1.096 & $29.34 \pm 1.83$ & $26.94 \pm 1.80$ & $38.27 \pm 1.82$ & $59.95 \pm 1.60$ & $64.85 \pm 1.59$ & -0.505 & $40.55 \pm 0.95$ \\
\hline 0.795 & $19.39 \pm 1.05$ & $20.47 \pm 0.81$ & $30.25 \pm 0.43$ & $50 \pm 0.00$ & $52.79 \pm 2.44$ & -0.806 & $30 \pm 0.00$ \\
\hline 0.494 & $9.69 \pm 0.52$ & $9.69 \pm 0.52$ & $28.61 \pm 1.36$ & $38.05 \pm 2.17$ & $40 \pm 0.00$ & -1.107 & $20 \pm 0.00$ \\
\hline 0.193 & $10 \pm 0.00$ & $10 \pm 0.0$ & $20.47 \pm 0.81$ & $30 \pm 0.00$ & $30 \pm 0.00$ & -1.408 & $10 \pm 0.00$ \\
\hline-0.107 & 0 & 0 & $8.58 \pm 0.43$ & $20 \pm 0.00$ & $20 \pm 0.00$ & -1.709 & $10 \pm 0.00$ \\
\hline-0.408 & - & - & - & - & $20 \pm 0.00$ & - & - \\
\hline-0.709 & - & - & - & - & $10 \pm 0.00$ & - & - \\
\hline $\mathrm{LC}_{50}$ value $(\mu \mathrm{g} / \mathrm{mL})$ & $48.71 \pm 0.70$ & $51.90 \pm 0.45$ & $17.22 \pm 0.14$ & $5.23 \pm 0.11$ & $5.03 \pm 0.08$ & & $0.46 \pm 0.05$ \\
\hline
\end{tabular}


Table 5 Summary of antimicrobial activity of Anethum sowa L. root extracts by diffusion method on Gram-positive bacteria

\begin{tabular}{|c|c|c|c|c|c|}
\hline \multirow[t]{2}{*}{ Extracts } & \multirow[t]{2}{*}{ Dose ( $\mu \mathrm{g} /$ well) } & \multicolumn{4}{|c|}{ Gram-positive bacteria and zone of inhibition in $\mathrm{mm}$} \\
\hline & & Bacillus subtilis & Bacillus cereus & Staphylococcus aureus & Enterococcus faecalis \\
\hline \multirow[t]{3}{*}{ PE (Cold) } & 400 & - & - & - & - \\
\hline & 1200 & $13.03 \pm 0.15$ & $5.03 \pm 0.05$ & $11.0 \pm 0.10$ & - \\
\hline & 2000 & $18.06 \pm 0.20$ & $8.0 \pm 0.10$ & $15.0 \pm 0.10$ & - \\
\hline \multirow[t]{3}{*}{ Hex (Hot) } & 400 & - & - & - & - \\
\hline & 1200 & $7.03 \pm 0.15$ & - & $7.1 \pm 0.10$ & - \\
\hline & 2000 & $10.0 \pm 0.20$ & - & $12.0 \pm 0.10$ & - \\
\hline \multirow[t]{3}{*}{ CE } & 400 & - & $6.06 \pm 0.05$ & - & - \\
\hline & 1200 & $7.03 \pm 0.20$ & $8.06 \pm 0.05$ & - & - \\
\hline & 2000 & $10.06 \pm 0.05$ & $11.03 \pm 0.25$ & - & - \\
\hline \multirow[t]{3}{*}{ EtOAc } & 400 & $10.03 \pm 0.15$ & $8.06 \pm 0.15$ & $6.06 \pm 0.11$ & - \\
\hline & 1200 & $14.03 \pm 0.11$ & $11.06 \pm 0.15$ & $8.03 \pm 0.11$ & $7.13 \pm 0.05$ \\
\hline & 2000 & $26.0 \pm 0.26$ & $15.03 \pm 0.20$ & $15.03 \pm 0.15$ & $12.03 \pm 0.25$ \\
\hline \multirow[t]{3}{*}{$\mathrm{MeOH}$} & 400 & - & - & - & - \\
\hline & 1200 & - & $7.06 \pm 0.11$ & - & $8.0 \pm 0.10$ \\
\hline & 2000 & - & $15.06 \pm 0.15$ & - & $10.03 \pm 0.25$ \\
\hline Std. CP & $5 \mu \mathrm{g} / \mathrm{disc}$ & $27.0 \pm 0.10$ & $29.0 \pm 0.20$ & $25.10 \pm 0.10$ & $21.13 \pm 0.11$ \\
\hline Std. TE & $30 \mu \mathrm{g} / \mathrm{disc}$ & $24.0 \pm 0.10$ & $21.03 \pm 0.15$ & $26.03 \pm 0.11$ & $16.03 \pm 0.15$ \\
\hline
\end{tabular}

PE (Cold) Petroleum ether cold extract, Hex (Hot) Hexane hot extract, CE Chloroform extract, EtOAc Ethyl acetate extract, MeOH Methanol extract, Std. CP Standard Ciprofloxacin, Std. TE Standard Tetracycline, "-" : no zone of inhibition. Each value is the mean \pm SD of three determinations $(n=3)$

Table 6 Summary of antimicrobial activity of Anethum sowa L. root extracts by diffusion method on Gram-negative bacteria

\begin{tabular}{|c|c|c|c|c|c|c|c|}
\hline \multirow[t]{2}{*}{ Sample } & \multirow[t]{2}{*}{ Dose ( $\mu \mathrm{g} /$ well) } & \multicolumn{6}{|c|}{ Gram-negative bacteria and zone of Inhibition in $\mathrm{mm}$} \\
\hline & & E.. coli 12079 & E. coli 2799 & P. aeruginosa & S. enteritidis 1375 & S. typhi & A. aceti \\
\hline \multirow[t]{3}{*}{$\overline{P E}($ Cold) } & 400 & - & $7.03 \pm 0.29$ & $9.0 \pm 0.26$ & - & - & - \\
\hline & 1200 & $12.06 \pm 0.25$ & $8.0 \pm 0.20$ & $10.0 \pm 0.15$ & $6.03 \pm 0.05$ & $6.03 \pm 0.05$ & $8.10 \pm 0.10$ \\
\hline & 2000 & $15.03 \pm 0.20$ & $13.10 \pm 0.42$ & $12.0 \pm 0.11$ & $9.03 \pm 0.05$ & $11.0 \pm 0.20$ & $10.06 \pm 0.11$ \\
\hline \multirow[t]{3}{*}{ Hex (Hot) } & 400 & - & - & - & - & - & - \\
\hline & 1200 & - & $6.0 \pm 0.10$ & $8.0 \pm 0.17$ & - & - & $7.03 \pm 0.15$ \\
\hline & 2000 & - & $9.03 \pm 0.12$ & $11.0 \pm 0.11$ & - & - & $11.03 \pm 0.25$ \\
\hline \multirow[t]{3}{*}{ CE } & 400 & - & $7.0 \pm 0.30$ & $7.10 \pm 0.10$ & - & - & - \\
\hline & 1200 & $7.03 \pm 0.15$ & $10.1 \pm 0.10$ & $8.07 \pm 0.11$ & - & - & $7.10 \pm 0.17$ \\
\hline & 2000 & $9.0 \pm 0.30$ & $12.0 \pm 0.21$ & $10.1 \pm 0.10$ & - & - & $10.06 \pm 0.11$ \\
\hline \multirow[t]{6}{*}{ EtOAc } & 400 & $7.06 \pm 0.25$ & $7.03 \pm 0.12$ & $9.0 \pm 0.10$ & - & $6.0 \pm 0.10$ & $6.03 \pm 0.05$ \\
\hline & 1200 & $11.03 \pm 0.28$ & $13.0 \pm 0.10$ & $12.0 \pm 0.05$ & - & $8.0 \pm 0.17$ & $7.06 \pm 0.11$ \\
\hline & 2000 & $13.06 \pm 0.30$ & $15.0 \pm 0.15$ & $14.0 \pm 0.17$ & - & $16.03 \pm 0.20$ & $12.0 \pm 0.26$ \\
\hline & 400 & - & - & - & - & - & - \\
\hline & 1200 & $6.03 \pm 0.05$ & $7.03 \pm 0.06$ & $9.03 \pm 0.05$ & - & - & $9.06 \pm 0.20$ \\
\hline & 2000 & $8.06 \pm 0.20$ & $10.0 \pm 0.17$ & $11.0 \pm 0.10$ & - & $7.06 \pm 0.05$ & $12.16 \pm 0.15$ \\
\hline Std. CP & $5 \mu \mathrm{g} / \mathrm{disc}$ & $25.03 \pm 0.40$ & $23.10 \pm 0.17$ & $29.0 \pm 0.11$ & $39.0 \pm 0.17$ & $35.03 \pm 0.37$ & $28.03 \pm 0.23$ \\
\hline Std. TE & $30 \mu \mathrm{g} / \mathrm{disc}$ & $9.03 \pm 0.30$ & $11.0 \pm 0.21$ & $16.10 \pm 0.15$ & $23.0 \pm 0.10$ & $25.03 \pm 0.20$ & $23.06 \pm 0.28$ \\
\hline
\end{tabular}

PE (Cold) Petroleum ether cold extract, Hex (Hot) Hexane hot extract, CE: Chloroform extract, EtOAc Ethyl acetate extract, MeOH Methanol extract, Std. CP Standard Ciprofloxacin, Std. TE Standard Tetracycline, "-" :no zone of inhibition. Each value is the mean \pm SD of three determinations $(n=3)$ 
Table 7 Minimum inhibitory concentration (MIC) of Anethum sowa L. root extracts

\begin{tabular}{|c|c|c|c|c|c|c|c|}
\hline \multirow[t]{2}{*}{ Test organisms } & & \multicolumn{6}{|c|}{ MIC value $(\mu \mathrm{g} / \mathrm{mL})$} \\
\hline & & PE (Cold) & Hex (Hot) & CE & EtOAc & $\mathrm{MeOH}$ & $C P$ \\
\hline \multirow[t]{4}{*}{ Gram positive bacteria } & Bacillus subtilis & 125 & 62.5 & 125 & 62.5 & 250 & 1.55 \\
\hline & Bacillus subtilis & 250 & 62.5 & 250 & 125 & 125 & 3.125 \\
\hline & Staphylococcus aureus & 250 & 250 & 500 & 125 & 250 & 6.25 \\
\hline & Enterococcus faecalis & 250 & 250 & 62.5 & 125 & 250 & 0.37 \\
\hline \multirow[t]{6}{*}{ Gram negative bacteria } & Escherichia coli 12079 & 500 & 500 & 500 & 62.5 & 250 & 0.75 \\
\hline & Escherichia coli 2799 & 250 & 250 & 62.5 & 62.5 & 250 & 0.37 \\
\hline & Pseudomonas aeruginosa, & 1000 & 250 & 250 & 125 & 125 & 3.125 \\
\hline & Salmonella enteritidis 1375 & 125 & 250 & 250 & 62.5 & 125 & 0.37 \\
\hline & Salmonella typhi & 250 & 250 & 250 & 125 & 125 & 0.19 \\
\hline & Acetobacter aceti & 125 & 125 & 62.5 & 62.5 & 250 & 0.37 \\
\hline
\end{tabular}

PE (Cold) Petroleum ether cold extract, Hex (Hot) Hexane hot extract, CE Chloroformextract, EtOAc Ethyl acetate extract, MeOH Methanol extract and $C P$ Ciprofloxacin

results revealed that all the Gram-positive organisms were resistant to the PE (Cold), Hex (Hot), CE and $\mathrm{MeOH}$ extracts at $400 \mu \mathrm{g} /$ well concentration except $B$. cereus in CE extract. It was observed that EtOAc extract produced the highest zone of inhibition against the Gram-positive bacteria $(12-26 \mathrm{~mm})$ which was followed by PE (Cold) $(8-18 \mathrm{~mm}), \mathrm{MeOH}(10-15 \mathrm{~mm})$, Hex (Hot) $(10-12 \mathrm{~mm})$ and $\mathrm{CE}$ extract $(10-11 \mathrm{~mm})$ at the dose of $2000 \mu \mathrm{g} / \mathrm{well}$. At the dose of $1200 \mu \mathrm{g} / \mathrm{well}$, EtOAc extract showed the highest activity against the Gram-positive bacteria $(7-14 \mathrm{~mm})$, PE (Cold) extract showed moderate (5-13) activity whereas, Hex (Hot), $\mathrm{CE}$ and $\mathrm{MeOH}$ extracts showed weak activity against all the Gram-positive bacteria. However, PE (Cold), Hex (Hot) and CE extracts did not produce any zone of inhibition against Enterococcus faecalis. Similarly, CE and $\mathrm{MeOH}$ extracts were also inactive against Staphylococcus aureus. Moreover, $\mathrm{MeOH}$ extract had no effect against
Bacillus subtilis. Whereas, the standard drugs ciprofloxacin $(5 \mu \mathrm{g} /$ disc $)$ and tetracycline $(30 \mu \mathrm{g} /$ disc $)$ inhibited the growth of entire Gram-positive bacteria with a significant zone of inhibition $21-29 \mathrm{~mm}$ and $16-26 \mathrm{~mm}$ respectively.

On the other hand, there was a significant variation was observed against the Gram-negative bacteria of the root extracts shown in Table 6. The EtOAc extract exhibited the highest activity $(12-16 \mathrm{~mm})$ followed by PE (Cold) $(9-15 \mathrm{~mm}), \mathrm{MeOH}(7-12 \mathrm{~mm}), \mathrm{CE}(9-12 \mathrm{~mm})$ and Hex (Hot) $(9-11 \mathrm{~mm})$ extracts at the dose of $2000 \mu \mathrm{g} /$ well. Hex (Hot), CE, EtOAc and MeOH extracts had no susceptibility against Salmonella enteritidis 1375. Similarly, Hex (Hot) and CE extract showed the same against Salmonella typhi and also Hex (Hot) extract in Escherichia coli 12079. MeOH and Hex (Hot) extract showed registrant of all the Gram-negative bacteria at the dose of $400 \mu \mathrm{g} /$ well. At the dose of $1200 \mu \mathrm{g} /$ well,

Table 8 Minimum bactericidal concentration (MBC) of Anethum sowa L. root extracts

\begin{tabular}{|c|c|c|c|c|c|c|c|}
\hline \multirow[t]{2}{*}{ Test organisms } & & \multicolumn{6}{|c|}{ MBC value $(\mu \mathrm{g} / \mathrm{mL})$} \\
\hline & & PE (Cold) & Hex (Hot) & CE & EtOAc & $\mathrm{MeOH}$ & $\mathrm{CP}$ \\
\hline \multirow[t]{4}{*}{ Gram-positive bacteria } & Bacillus subtilis & 250 & 125 & 250 & 125 & 500 & 12.5 \\
\hline & Bacillus cereus & 500 & 125 & 500 & 500 & 500 & 25 \\
\hline & Staphylococcus aureus & 500 & 500 & 1000 & 1000 & 500 & 50 \\
\hline & Enterococcus faecalis & 1000 & 1000 & 125 & 500 & 500 & 100 \\
\hline \multirow[t]{6}{*}{ Gram-negative bacteria } & Escherichia coli 12079 & 1000 & 1000 & 1000 & 125 & 500 & 50 \\
\hline & Escherichia coli 2799 & 500 & 500 & 125 & 125 & 500 & 6.25 \\
\hline & Pseudomonas aeruginosa, & 1000 & 500 & 500 & 250 & 250 & 25 \\
\hline & Salmonella enteritidis 1375 & 250 & 500 & 500 & 500 & 250 & 6.25 \\
\hline & Salmonella typhi & 500 & 500 & 500 & 500 & 250 & 3.125 \\
\hline & Acetobacter aceti & 500 & 250 & 125 & 250 & 500 & 50 \\
\hline
\end{tabular}

PE (Cold) Petroleum ether cold extract, Hex (Hot) Hexane hot extract, CE Chloroform extract, EtOAc Ethyl acetate extract, MeOH Methanol extract and CP Ciprofloxacin 
EtOAc $(7-13 \mathrm{~mm})$ and PE (Cold) $(6-12 \mathrm{~mm})$ extract showed moderate activity to the Gram-negative bacteria. Comparing the results with ciprofloxacin $(5 \mu \mathrm{g} / \mathrm{disc})$ and tetracycline $(30 \mu \mathrm{g} / \mathrm{disc})$, the entire Gram-negative bacteria inhibited to the extracts with a significant zone of inhibition $23-39 \mathrm{~mm}$ and $9-25 \mathrm{~mm}$ respectively. Again, the better activity was demonstrated with $2000 \mu \mathrm{g} / \mathrm{mL}$ concentration of all the tested extracts. The results demonstrate that Gram-positive bacteria are more sensitive to the extracts than the Gram-negative bacteria.

This higher resistance among Gram-negative bacteria could be due to the differences in the cell membrane of this bacterial group. The Gram-negative bacteria possess an outer membrane and a unique periplasmic space which is not found in the Gram-positive bacteria [46]. The resistance of Gram-negative bacteria towards antibacterial substances is related to the hydrophilic surface of their outer membrane which is rich in lipopolysaccharide molecules, presenting a barrier to the penetration of numerous antibiotic molecules and it is also associated with the enzymes in the periplasmic space, which are capable of breaking down the molecules introduced from outside [47]. The Gram-positive bacteria do not have such an outer membrane and cell wall structure. Antibacterial substances can easily destroy the bacterial cell wall and cytoplasmic membrane and result in a leakage of the cytoplasm and its coagulation [48]. However, $\mathrm{MeOH}$ extract did not show the trend completely in this study.

The MIC is the lowest concentration of the agent that completely inhibits visible growth, disregarding a single colony or a thin haze within the area of the inoculated spot [49]. Anethum sowa L. root extracts were tested with agar-dilution assay and susceptibilities were compared with a ciprofloxacin (positive control) at the different concentration by serial dilution technique. The results are shown in Table 7. The lowest MICs $(62.5 \mu \mathrm{g} / \mathrm{mL})$ was observed in EtOAc extract against B. subtilis, E. coli 12079, E. coli 2799, S. enteritidis 1375 and $A$. aceti. Moreover, the best activity possessed antibacterial activities with MICs of 62.5-125 $\mu \mathrm{g} / \mathrm{mL}$ of EtOAc, CE and Hex(Hot) extracts followed by $\mathrm{MeOH}$ extract $(125-250 \mu \mathrm{g} / \mathrm{mL})$. However, PE (Cold), Hex (Hot) and CE extracts showed weak inhibition (MIC $500 \mu \mathrm{g} / \mathrm{mL}$ ) in the test tubes containing Escherichia coli 12079. On the other hand, PE (Cold) extract showed the very weak against Pseudomonas aeruginosa. Overall, the Gram-positive bacteria showed the stronger activity than Gram-negative bacteria of the MIC experiment. However, standard ciprofloxacin showed the complete inhibition (i.e. no turbidity) against all of the test bacteria. S. aureus and B. cereus are well-known for being resistant to numerous antibiotics. Moreover, these organisms are capable of producing several types of enterotoxins that can cause septicaemia and several forms of enteritis. These findings are of promising in the case of EtOAc extract that was found to be active against these bacterial species.

In the MBC experiment (Table 8), the most susceptible bacteria to the EtOAc extract were Bacillus subtilis, Escherichia coli 12079 and Escherichia coli 2799 followed by CE extract against Enterococcus faecalis, Escherichia coli 2799 and Acetobacter aceti and Hex (Hot) extract against Bacillus subtilis and Bacillus cereus presenting an important growth of inhibition at the lowest concentration of $\mathrm{MBC}$ at $125 \mu \mathrm{g} / \mathrm{mL}$. $\mathrm{MeOH}$ extract showed moderate effect against Pseudomonas aeruginosa, Pseudomonas aeruginosa and Salmonella typhi with $\mathrm{MBC}$ value of $250 \mu \mathrm{g} / \mathrm{mL}$. Furthermore, PE (Cold), Hex (Hot), CE and EtOAc extract showed less potent activity at the dose of $1000 \mu \mathrm{g} / \mathrm{mL}$. against Staphylococcus aureus, Enterococcus faecalis, Escherichia coli 12079 and Pseudomonas aeruginosa. On the other hand, standard ciprofloxacin showed the most susceptible to Grampositive and Gram-negative bacteria than the experimental extracts.

Microbial contamination still poses an important public health and economic concerns for human society. For these reasons, there has been increasing interest in searching of natural antimicrobial agents and it has notably increased for healthy lifestyles and healthy ageing. The screening of the chemical groups found in root extracts showed the presence of tannins, flavonoids and anthraquinone. The presence of these constituents at the high concentration may possess antimicrobial properties in the different extracts. Again, the antimicrobial effects of tannins take place by involving different mechanisms such as inhibition of extracellular microbial enzymes, deprivation of the substrates required for microbial growth or direct action on microbial metabolism through inhibition of oxidative phosphorylation [50]. Flavonoids and tannins are effective antimicrobial substances possibly due to their capability to form a complex with the extracellular and the soluble protein and to intricate with the cell membrane leading to the death of the bacteria [51]. Moreover, the plant extract was also positive for steroids which are very important compounds because it has a relationship with compounds such as sex hormone and also reported as antibacterial properties $[52,53]$. The presence of the steroids in PE (Cold) extract justifies the antibacterial property of this plant part. Accordingly, the presence of these molecules in the active fractions might play an important role in the observed antibacterial activity. Their mode of action probably depends on the individual microorganism which could explain the large differences in MIC values between bacteria.

The antifungal activity of Anethum sowa root extracts were measured and represented in Table 9. The extracts 


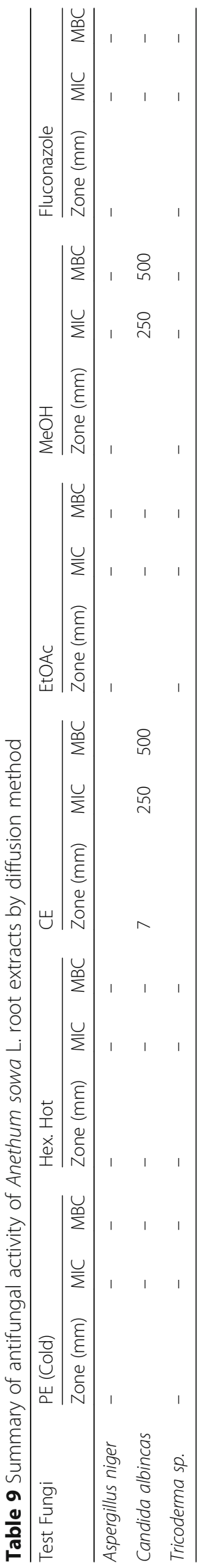


did not show any growth of inhibition against Aspergillus niger and Tricoderma sp. except Candida albincas which showed some weak activity to the $\mathrm{CE}$ and $\mathrm{MeOH}$ extract. The results were compared with the standard drug, Fluconazole $(100 \mu \mathrm{g} / \mathrm{disc})$. The root extracts contain a number of secondary metabolites in the current studies. The isolation and purification of the extract may discover many significant novel antimicrobial lead compounds.

\section{Conclusion}

Despite ongoing scientific research on this species, this study constitutes the first attempt to compile the phytochemical compositions as well as the antioxidant, antimicrobial and cytotoxic activities of Anethum sowa L. root extracts that could be found despite the throughout literature survey so far as we know. The knowledge of phytochemical constituents of the plant is the basic approach to identify novel secondary metabolites as unmodified form, semi-synthetic or drug templates. However, the mixture of biologically active compounds present in the different extract with different structures and also their synergistic effects may enhance the overall effect of the particular extract though their exact mode of action is poorly understood. This study delineates that methanol, ethyl acetate and chloroform extract could be a potentials in free-radical scavenging activity and cytotoxic effect and moderate antimicrobial activity. Since, crude methanol and ethyl acetate extract found to have moderate antibacterial activity. So, it can be assumed that different active secondary metabolites were present in these extracts. Furthermore, the activity of this plant constituent can help to elucidate the justification for the ethnomedicinal use of this plant species scientifically. Based on our findings, further studies are necessary to elucidate the mechanism lying with these effects of the plant extracts and could be open a new window in the search for new bioactive drug lead components of this plant extracts.

\section{Abbreviations}

ASA: Ascorbic acid; BHT: Butylated hydroxytoluene; CE: Chloroform; DMSO: Dimethyl sulfoxide; DPPH: 2,2-diphenyl-1-picrylhydrazyl; EtOAc: Ethyl acetate; Hex: Hexane; MBC: Minimum bactericidal concentrations; MeOH: Methanol; MIC: Minimum inhibitory concentration; PE: Pet-ether; ROS: Reactive oxygen species; TSA: Tryptone soy agar; VcS: Vincristine sulfate

\section{Acknowledgements}

The authors would like to thank the Bangladesh Council of Scientific and Industrial Research for laboratory facilities and awarding the Dr. Qudrat-i-Khuda doctoral fellowship to the first author of this research work.

\section{Funding}

Not applicable.

\section{Availability of data and materials}

The datasets generated and/or analysed during the current study are available from the corresponding author on reasonable request.

\section{Authors' contributions}

MMS-e-In: Participated in all face of the study, collection plant, conceived of the study, design and wrote the manuscript. MRI, NS: Supervised part of the study and reviewed the manuscript. MNH, SH: Coordinated and conducted antimicrobial assay and provided all necessary materials for the assay. All authors read and approved the final manuscript.

\section{Competing interests}

The authors declare that they have no competing interests.

Consent for publication

Not applicable.

Ethics approval and consent to participate

Not applicable.

\section{Author details}

'Department of Chemistry, Jahangirnagar University, Savar 1342, Dhaka, Bangladesh. ${ }^{2}$ Institute of National Analytical Research and Services, BCSIR Laboratories, Bangladesh Council of Scientific and Industrial Research, Dhaka 1205 Bangladesh. ${ }^{3}$ Industrial Microbiology Research Division, Institute of Food Science and Technology, Bangladesh Council of Scientific and Industrial Research, Dhaka 1205 Bangladesh. ${ }^{4}$ Department of Microbiology, Jagannath University, Dhaka 1100 Bangladesh.

Received: 26 March 2016 Accepted: 27 October 2016

Published online: 14 November 2016

\section{References}

1. Chew AL, Jessica JJA, Sasidharan S. Antioxidant and antibacterial activity of different parts of Leucas aspera. Asian Pac J Trop Biomed. 2012;2(3):176-80.

2. Ullah MO, Haque M, Urmi KF, ZulfiKer AHM, Anita ES, Begum M, Hamid K. Anti-bacterial activity and brine shrimp lethality bioassay of methanolic extracts of fourteen different edible vegetables from Bangladesh. Asian Pac J Trop Biomed. 2013;3(1):1-7.

3. Singh G, Maurya S, Lampasona MPD, Catalan C. Chemical constituents, antifungal and antioxidative potential of Foeniculum vulgare volatile oil and its acetone extract. Food Control. 2006;17:745-52.

4. Sahreen $\mathrm{S}$, Khan MR, Khan RA. Evaluation of antioxidant activities of various solvent extracts of Carissa opaca fruits. Food Chem. 2010;122:1205-11.

5. Anonymous. The wealth of India. A raw materials, vol. 1. New Delhi: Council of Scientific and Industrial Research; 1985. p. 272-5.

6. Chopra RN, Nayer SL, Chopra IC. A Glossary of Indian medicinal plants and supplements, publication and information directorate, vol. 3. New Delhi: CSIR; 1992. p. 216-7.

7. Woolf A. Essential oil poisoning. J Clin Toxicol. 1999;37(6):721-7.

8. Tomar SS, Maheshwari ML, Mukerjee SK. Synthesis and synergistic activity of dillapiole based pyrethrum synergists. J Agric Food Chem. 1979;27(3):547.

9. Singh G, Maurya S, Lampasona MPD, Catalan C. Chemical constituents, antimicrobial investigations and anti-oxidative potentials of Anethum graveolens L. essential oil and acetone extract: part 52. J. Food Sci. 2005;70(4):208-15.

10. Mansouri ElL, Bousta D, Youbi-El ElHA, Boukhira S, Akdime H. Phytochemical screening, antidepressant and analgesic effects of aqueous extract of Anethum graveolens L. from south-east of Morocco. Am J Ther. 2016. [Epub ahead of print]. doi:10.1097/MJT.0000000000000090.

11. Abbasi OE, Khodadadi I, Saidijam M, Yadegarazari R, Shabab N, Tavilani H, Goodarzi MT. Lipid lowering effects of hydro-alcoholic extract of Anethumgraveolens $L$ and dill tablet in high cholesterol fed hamsters. Cholesterol. 2015;2015:958560. doi:10.1155/2015/958560.

12. Sati SC, Sati N, Rawat U, Sati OP. Medicinal plants as a source of antioxidants. Res J Phytochemistry. 2010;4:213-24.

13. Madhuri S, Pandey G. Some anticancer medicinal plants of foreign origin. Curr Sci. 2009;96(6):779-83.

14. Surveswaran S, Cai Y-Z, Corke H, Sun M. Systematic evaluation of natural phenolic antioxidants from 133 Indian medicinal plants. Food Chem. 2007:102:938-53.

15. Parimala M, Shoba FG. In vitro antimicrobial activity and HPTLC analysis of hydroalcoholic seed extract of Nymphaea nouchali Burm f'. BMC Complement Alt Med. 2014;14:361. 
16. Mclaughlin JL, Rogers LL, Anderson JE. The use of biological assays to evaluate botanicals. Drug Inf J. 1998;32:513-24.

17. Meyer BN, Ferrigni NR, Putnam JE, Jacobsen JB, Nicholsand DE, Mclaughlin JL. Brine shrimp; a convenient general bioassay for active plant constituents. Planta Med. 1982;45:31-4.

18. Ghani A. Medicinal plants of Bangladesh (chemical constituents and uses), vol. 2. Dhaka: Asiatic Society of Bangladesh; 2003. p. 497-505.

19. Harborne JB. Phytochemical methods. London: Chapman and Hall, Ltd; 1973. p. 49-188.

20. Raman N. Phytochemical Technique. New Delhi: New India Publishing agency; 2006.

21. Brand-Williams W, Cuvelier ME, Berset C. Use of a free radical method to evaluate antioxidant activity. Lebensm Wiss Technol. 1995;28:25-30. doi:10.1016/S0023-6438(95)80008.

22. Sein $\pi$, Spurio $R$, Cecchini $C$, Cresci A. Screening for microbial strains degrading glass fibre acrylic composite filters. Int Biodeterior Biodegrad. 2008;63:901-5.

23. Bauer AW, Kirby WM, Sherris JC, Turck M. Antibiotic susceptibility testing by a standardized single disk method. Am J Clin Pathol. 1966:45:493-6.

24. Rahman A u, Choudhary MI, Thomson WJ. Bioassay Techniques for Drug Development. UK: Harwood Academic Publishers; 2005. p. 13-4.

25. Parish ME, Davidson PM. Methods for evaluation: In antimicrobials in foods, vol. 2. New York: Marcel Dekker, Inc; 1993. p. 597-615.

26. Burt S. Essential oils: their antibacterial properties and potential applications in foods. A review. Int J Food Microbial. 2004;94:223-53.

27. Alison AW, George WJF, Naoki A, Russell JM, Robert JN. Polyhydroxylated alkaloids-natural occurrence and therapeutic applications. Phytochemistry. 2001:56:265-95

28. Bhandarkar M, Khan A. Protective effect of Lawsonia alba Lam. Against $\mathrm{CCl}_{4}$ induced hepatic damage in albino rats. Indian J Exp Biol. 2003:41:85-7.

29. Krishnaiah D, Devi T, Bono A, Sarbatly R. Studies on phytochemical constituents of six Malaysian medicinal plants. J Med Plant Res. 2009;3(2):067-72.

30. Kasolo JN, Bimenya GS, Ojok L, Ochleng J, Ogwal-Okeng JW. Phytochemicals and uses of Moringa oleifera leaves in Ugandan rural communities. J Med Plant Res. 2010:4:753-7.

31. Polterait $\mathrm{O}$. Antioxidants and free-radical scavengers of natural origin. Current Org Chem. 1997:1:415-40.

32. Price KR, Johnson TI, Fenwick GR. The chemistry and biological significance of saponins in food and feeding stuffs. Crit Rev Food Sci Nutr. 1987;26:22-48.

33. Dhar ML, Dhar MM, Dhawan BN, Ray C. Screening of Indian plants for biological activity, Part-I. Ind J Biology. 1979;6:232-4.

34. Cherian S, Augusti KT. Insulin sparing action of leucopelargonidin derivative isolated from Ficus bengalesis Linn. Indian J Exp Biol. 1995;33:608-11.

35. Anyasor GN, Ogunwenmo KO, Oyelana OA, Akpofunure BE. Phytochemical constituents and antioxidant activities of aqueous and methanolic stem extracts of Costus afer Ker Gawl (Costaceae). Afr J Biotechnol. 2010;9(31):4880-4.

36. Agbaire PO, Emoyan OO. Nutritional and antinutritional levels of some local vegetables from Delta State, Nigeria. Afr J Food Sci. 2012;6(1):8-11.

37. Nwinuka NM, Ibeh GO, Ekeke GI. Proximate composition and levels of some toxicants in four commonly consumed spices. J Appl Sci Environ Manag. 2005;9(1):150-5

38. Rupasinghe HP, Jackson CJ, Poysa V, Bierado CD, Bewley JD, Jenkinson J. Soyasapogenol A and B distribution in Glycine max in relation to seed physiology, genetic variability and growing location. J Agric Food Chem. 2003;51:5888-94.

39. Albayrak S, Aksoy A. Biological activities of Wiedemannia multifida L. Benthum and Wiedemannia orientalis Fisch. \& Mey. Asian Pac J Trop Biomed. 2013;3(3):196-201.

40. Bendary E, Francis RR, Ali HMG, Sarwat MI, Hady SEl. Antioxidant and structure-activity relationships (SARs) of some phenolic and anilines compounds. Ann Agric Sci. 2013:58(2):173-81.

41. Oketch-rabah HA, Dossaji JF, Mberu EK. Antimalarial activity of some Kenyan medicinal plants. Pharm Biol. 1999;37:329-34.

42. Subhadra S, Kanacharalapalli VR, Ravindran VK, Parre SK, Chintala S, Thatipall R. Comparative toxicity assessment of three Tephrosia species on Artemia salina and animal cell lines. J Nat Pharma. 2011;2(3):143-7.

43. Jerry LM, Lingling LR. The use of biological assays to evaluate botanicals. Drug Inf J. 1998;32:513-24.
44. Özçelik B, Kartal M, Orhan I. Cytotoxicity, antiviral and antimicrobial activities of alkaloids, flavonoids and phenolic acids. Pharm Biol. 2011;49(4):396-402. doi:10.3109/13880209.2010.519390.

45. Mazid MA, Datta BK, Nahar L, Sarker SD. Assessment of anti-bacterial activity and brine shrimp toxicity of two Polygonum species. Ars Pharmaceutica. 2008;49(2):135-44

46. Duffy CF, Power RF. Antioxidant and antimicrobial properties of some Chinese plant extracts. Int J Antimicrob Agents. 2001;17:527-9.

47. Gao Y, Van BMJ, Stiles ME. The outer membrane of Gramnegative bacteria inhibits antibacterial activity of brochocin-C. Appl Environ Microbiol. 1999:65:4329-33.

48. Kalemba D, Kunicka A. Antibacterial and antifungal properties of essential oils. Curr Med Chem. 2003:10:813-29.

49. Ntsoelinyane PMAH, Mashele S. Phytochemical screening, antibacterial and antioxidant activities of Asparagus laricinus leaf and stem extracts. Bangladesh J Pharmacol. 2014;9(1):10-4.

50. Scalbert A. Antimicrobial properties of tannins. Phytochemistry. 1991;30(12): 3875-83.

51. Cowan M. Plant products as antimicrobial agents. Clin Microbiol Rev. 1999:12:564-82.

52. Okwu DE. Evaluation of the chemical composition of medicinal plants belonging to Euphorbiaceae. Pak Vet J. 2001;14:160-2.

53. Epand RF, Savage PB, Epand RM. Bacterial lipid composition and the antimicrobial efficacy of cationic steroid compounds (Ceragenins). Biochem Biophys Acta. 2007;1768(10):2500-9.

\section{Submit your next manuscript to BioMed Central and we will help you at every step:}

- We accept pre-submission inquiries

- Our selector tool helps you to find the most relevant journal

- We provide round the clock customer support

- Convenient online submission

- Thorough peer review

- Inclusion in PubMed and all major indexing services

- Maximum visibility for your research

Submit your manuscript at www.biomedcentral.com/submit 